\title{
Mycotoxins and its impact on human populations
}

\section{Introduction}

Food spoilage due to microorganism's especially fungal contamination can be accompanied by the production of toxic secondary metabolites which may result in medical problems. Mycotoxins are secondary metabolites and structurally diverse group of mostly small molecular weight compounds produced by different molds or fungi that have shown serious effects on humans, animals, and crops. Not all toxins produced by molds are called Mycotoxins. The contamination of food materials with molds and mycotoxins is a major concern worldwide. Mycotoxins are toxic to human beings and other animals even in very low concentrations. Mostly, mycotoxins occur more frequently in areas with a hot and humid climate that favors the growth of molds in the substrate. But they can also be found in temperate as well as other climatic conditions. Many molds are capable of producing more than one type of mycotoxin. Some mycotoxins are produced by more than one species. Generally, more than one mycotoxin is found on a contaminated food substrate.

Exposure to mycotoxins is mostly by ingestion, but also may occur through dermal and inhalation routes (fungal bioaerosols). Some fungal species produce mycotins in their spores or in mycelium. The diseases caused by exposure to mycotoxins are known as mycotoxicoses. However, mycotoxicoses often remain unrecognized by medical professionals. Mycotoxins such as Aflatoxin $\mathrm{B}_{1}\left(\mathrm{AFB}_{1}\right)$, fumonisin $\mathrm{B}_{1}\left(\mathrm{FB}_{1}\right)$ \& ochratoxin $\mathrm{A}(\mathrm{OTA})$ which are toxic to mammals causing one of the most toxic effects on them leading to hepatotoxicity, mutagenicity, tetragenicity resulting in diseases like hepatitis, oedema, haemorrhage, oesophageal cancer \& kidney failure. ${ }^{1,2}$ The presence of fungal propagules, volatiles and mycotoxins in the air can cause a health hazard in all segments of the population. ${ }^{3,4}$

The reason for the production of mycotoxins is still unknown but studies have said that they are not necessary for the growth. As mycotoxins weaken the receiving host, the fungus uses them as a source to better the environment for further fungal proliferation. Mycotoxin enhances the production of oxygen free-radicals \& inhibits protein synthesis by competition with phenylalanine its structural analogue. Aspergillus, Penicillium \& Fusarium are common fungal species producing mycotoxin which are frequently occurred in major food crops in agricultural field \& contaminate during transportation and storage. Study reports of outbreaks mycotoxicoses disease in animals \& humans have been reported after consumption of these contaminated food stuff causing severe health hazards.

\section{These mycotoxins are classified as following}

Aflatoxin: The major aflatoxins are called $\mathrm{B}_{1}, \mathrm{~B}_{2}, \mathrm{G}_{1} \& \mathrm{G}_{2}$ found in cereals, fruits \& food products and $M_{1} \& M_{2}$ (produced in milk and dairy products when cows consume aflatoxin-contaminated feeds), they metabolically bio-transform aflatoxin $\mathrm{B}_{1}$ into a hydroxylated form called aflatoxin $M_{1}$. Aflatoxin is associated with both toxicity and carcinogenicity in human and animal populations. According to International Agency for Research on $\mathrm{Cancer}^{5}$ has classified Aflatoxin $\mathrm{B}_{1}\left(\mathrm{AFB}_{1}\right)$ as a Class 1 human carcinogen. Aflatoxin $\mathrm{B}_{1}$ is the most potent natural carcinogen known and is usually the major aflatoxin produced by toxigenic strains.
Volume 3 Issue 5 - 2017

\author{
Umesh B Kakde \\ The Institute of Science, India
}

Correspondence: Umesh B Kakde, The Institute of Science, Madame Cama Road, Mumbai-32, India, Email drumeshkakde@gmail.com

Received: July 26, 2017 | Published: August 16, 2017

Ochratoxin: Ochratoxins are of two types Ochratoxin A \& Ochratoxin B. Ochratoxin A (OTA) is a secondary metabolite produced by several species of Aspergillus and Penicillium. The toxin, which is a nephrotoxic and nephrocarcinogenic compound, has mainly been found in many foodstuffs such as cocoa beans, milk, wine, fish, cereals, coffee beans, peanuts, dried fruits, poultry eggs, beer and grape juice. It occurs in the kidney, liver and blood of farm animals by transfer from animal feed. The principal classes of mycotoxins include a metabolite of A. flavus and Aspergillus parasiticus, aflatoxin $\mathrm{B}_{1}\left(\mathrm{AFB}_{1}\right)$, the most potent hepatocarcinogenic substance known, which has been recently proven to also be genotoxic.

Zearlenone: A non-steroidal estrogenic mycotoxin produced by species of Fusarium frequently found in a number of cereal crops \& their derived food products. It has an osteogenous action and is significantly toxic to the reproductive system of animals.

Patulin: Patulin is a toxic fungal metabolite (mycotoxin) produced by certain moulds of the genera Penicillium, Aspergillus. Chemically, patulin is a polyketide lactone and most commonly found in rotting apples and other fruits. In addition, patulin has been found in other foods such as grains, fruits, \& vegetables. Patulin produce a number of toxic effects in humans and its presence in food is undesirable due to its toxicity. It is a relatively small molecule $\left(\mathrm{C}_{7} \mathrm{H}_{6} \mathrm{O}_{4}\right)$ and is soluble in water. At relatively high doses, patulin is acutely toxic in some animals, causing gastrointestinal lesions, distension and haemorrhage in the stomach and small intestine.

All these compounds cause some degree of acute toxicity when given in high amounts. ${ }^{6-9}$ Over 40 species of Aspergillus have been listed as capable of producing toxic metabolites. Aspergillus mycotoxins of greatest significance in foods and feeds are aflatoxins which were known to produce by Aspergillus flavus, Aspergillus parasiticus $A$. fumigates. ${ }^{10,11}$ The reasons for the lack of action to handle the problem of mycotoxins have different angles in the developing countries like India. However, a number of factors can be identified viz. lack of knowledge, severity of the mycotoxin problems and health effects, hygienic storage and handling of the food materials etc. Because of its widespread human exposure to high levels and its carcinogenic properties the World Health Organization has started to respond and highlight the need for action. ${ }^{12,13}$

In many developing and underdeveloped countries mycotoxins affect staple foods, including groundnuts (peanuts), maize (corn), other 
cereals and nuts, such that exposure is continuous and often at high levels. Surveillance studies showed that worldwide contamination of cereal grains and other feeds with Fusarium mycotoxins..$^{14}$ Mycotoxins contaminate the diet of a large proportion of the world's population due to lake of proper handling and storage facilities and hot and humid conditions which favors the growth of fungi in food materials. Mostly the problems of mycotoxicoses described are a consequence of the ingestion of food contaminated with mycotoxins. The strict control of food quality, modern processing and storage facilities, legislation in both industrialized, developing and underdeveloped countries, is therefore necessary to avoid such outbreaks.

\section{Acknowledgements}

None.

\section{Conflict of interest}

The author declares no conflict of interest

\section{References}

1. Dönmez-Altuntaș H, Hamurcu Z, Imamoglu N, et al. Effects of ochratoxin an on micronucleus frequency in human lymphocytes. Nahrung. 2003;47(1):33-35

2. Negedu A, Atawodi SE, Ameh JB, et al. Economic \& health perspectives of mycotoxins: a review. Continental $J$ of Biomedical Sciences. $2011 ; 5(1): 5-26$

3. Kakde Umesh B, Hemalata U Kakde, Arati A Saoji. Seasonal variation of fungal propagules in a fruit market environment, Nagpur (India). Int $J$ Aerobiologia. 2001;17(2):177-182.
4. Pitt JI. Toxigenic fungi: which are important? Med Mycol. 2000;38(Suppl 1):17-22.

5. IARC. Some naturally occurring substances: food items and constituents, heterocyclic aromatic amines and mycotoxins. IARC Monogr Eval Carcinog Risks Hum. 1993;56:599.

6. Kramer CL, Pady SM, Rogerson CT. Kansas aeromycology Y: Penicillium and Aspergillus. Mycologia. 1961;52(4):545-551.

7. Willie TD, Morehouse LG. Mycotoxic fungi, mycotoxins and mycotoxicosis. New York: Mareal Dekkar Inc; 1978.

8. Bullerman LB. Significance of mycotoxins to food safety and human health. Journal of Food Protection. 1979;42(1):65-86.

9. Wicklow DT, Shotwell OL. Intra: fungal distribution of aflatoxin among conidia and sclerotia of Aspergillus flavus and A. parasiticus. Can J Microbiol. 1983;29(1):1-5.

10. Cole RJ, Schweikert BJ. Handbook of Secondary Fungal Metabolites. Vols. I and II. New York: Academic Press; 2003.

11. Kakde Umesh B. Fungal Bioaerosols: global diversity, distribution and its impact on human beings and agricultural crops. Bionano Frontier. 2012;5(2-II):323-329.

12. Milićević DR, Skrinjar M, Baltić T. Real and perceived risks for mycotoxin contamination in foods and feeds: challenges for food safety control. Toxins (Basel). 2010;2(4):572-592.

13. Peraica M, Radić B, Lucić A, et al. Toxic effects of mycotoxins in humans. Bull World Health Organ. 1999;77(9):754-766.

14. Placinta CM, D’Mello JPF, MacDonald AMC. A review of worldwide contamination of cereal grains and animal feed with Fusariam mycotoxins. Anim Feed Sci Technol. 1999;78:21-37. 